\title{
Desain Charger Control Pembangkit Listrik Tenaga Hybrid Dengan Pengaturan Duty Cycle PWM
}

\author{
Leily W Johar \\ Fakultas Teknik, Universitas Batanghari \\ Program Studi Teknik Listrik, Fakultas Teknik, Universitas Batanghari \\ ${ }^{*}$ Corresponding author, e-mail: leily.wustha.johar@unbari.ac.id
}

\begin{abstract}
Abstrak_ Penggunaan tegangan sumber DC yang diperoleh dari sel surya dan generator DC nilainya bervariasi tergantung kondisi alam sekitar, untuk itu dibutuhkan kontroler yang berfungsi mengatur tegangan tersebut dalam melakukan proses pengisian ke akumulator. Pada paper ini akan dibahas tentang rancang bangun charge controller berbasis Arduino Uno R3 dengan mikrokontroler ATmega328. Kontroler ini digunakan untuk mengatur proses charging yang berasal dari sumber DC dengan tegangan open circuit maksimum 24 Volt, yang kemudian digunakan untuk men-charge akumulator 12 Volt. Charge controller ini bekerja dengan cara mengirimkan tegangan sumber yang diatur modulasi lebar pulsa gelombangnya atau pulse width modulation. Pada saat tegangan akumulator $\leq 13,8$ Volt, kontroler akan melakukan proses charging dengan duty cycle $95 \%$, apabila tegangan akumulator $>13,8$ Volt dan $\leq 14,4$ Volt, charging akan dilakukan dengan duty cycle $10 \%$, dan jika tegangan akumulator melebihi 14,4 Volt, proses charging akan dihentikan. Beberapa peralatan proteksi juga terdapat pada charge controller ini seperti proteksi tegangan lebih, arus lebih dan juga pengontrolan pemutus hubungan ke beban apabila tegangan akumulator sudah lemah, dan pemutus hubungan dari sumber ke akumulator apabila kondisi akumulator sudah penuh. Untuk memperlihatkan kerja sistem secara keseluruhan maka dengan mikrokontroler Arduino Uno R3 parameter tegangan sumber, tegangan akumulator dan persentase status akumulator di tampilan pada layar LCD kemudian 2 lampu LED dan buzzer sebagai indikator pada saat proses charging berlangsung dan pada saat kondisi akumulator lemah. Dari hasil pembacaan tegangan pada sensor pembagi tegangan memiliki error kurang dari 6,22\% pada terminal sumber, dan 6,89\% pada terminal akumulator.
\end{abstract}

Kata Kunci : Charger, Duty Cycle, PWM

\begin{abstract}
The use of DC source voltage obtained from solar cells and DC generators varies in value depending on the surrounding natural conditions, for that a controller is needed which functions to regulate the voltage in carrying out the charging process to the accumulator. This paper will discuss about the design of charge controller based on Arduino Uno R3 with ATmega328 microcontroller. This controller is used to regulate the charging process from a DC source with a maximum open circuit voltage of 24 Volts, which is then used to charge the 12 Volt accumulator. This charge controller works by sending a source voltage that is regulated by pulse width modulation. When the accumulator voltage is 13.8 Volt, the controller will carry out a charging process with a duty cycle of $95 \%$, if the accumulator voltage is $>13.8$ Volts and $<14.4$ Volts, charging will be carried out with a duty cycle of $10 \%$, and if the accumulator voltage exceeds 14.4 Volt, the charging process will be stopped. Some protection equipment is also included in this charge controller such as overvoltage protection, overcurrent and also control of the connection breaker to the load when the accumulator voltage is weak, and a disconnect from source to accumulator when the accumulator condition is full. To show the work of the whole system, with the Arduino Uno R3 microcontroller the parameters of source voltage, accumulator voltage and percentage of accumulator status are displayed on the LCD screen then 2 LED lights and a buzzer as indicators during the charging process and when the accumulator condition is weak. From the results of the voltage reading on the voltage divider sensor, it has an error of less than $6.22 \%$ at the source terminal and $6.89 \%$ at the accumulator terminal..
\end{abstract}

Keywords : Charger, Duty Cycle, PWM

\section{PENDAHULUAN}

Charge controller merupakan suatu peralatan elektronika yang juga merupakan salah satu komponen bagian dari sistem pembangkit listrik tenaga hybrid yang mempunyai fungsi untuk mengatur proses pengisisan aki dan juga sebagai tempat terhubungnya sumber, akumulator, dan beban[1]. Alat ini mampu mengontrol proses pengisian energi listrik yang masuk ke akumulator dari sumber, dan memiliki fungsi untuk mencegah kelebihan pengisisan (overcharging) yang dapat mengurangi umur penggunaan akumulator dan mencegah terjadinya kegagalan dalam penggunaan. Tegangan sumber DC yang diperoleh dari sel surya dan generator DC nilainya bervariasi tergantung kondisi alam sekitar, sehingga kontroler ini berfungsi untuk mengatur tegangan tersebut untuk melakukan proses pengisian ke akumulator dan menjaga akumulator, agar proses pengisian tidak melewati batas toleransi daya yang mampu disimpan, untuk mencegah kerusakan pada akumulator dan menjaga umur pemakaian agar lebih tahan lama[2]. Alat ini juga mencegah arus balik yang dapat mengalir kembali ke sumber, karena apabila sumber dalam kondisi tidak mensuplai, sumber dapat bertindak sebagai beban pada kondisi tersebut, sehingga penggunaan daya akumulator dapat dikonsumsi dengan maksimal. Pengontrolan ini merupakan fungsi dasar dari sebuah charge controller. Pada paper ini beberapa peralatan proteksi juga terdapat pada charge controller 
ini seperti proteksi tegangan lebih, arus lebih dan juga pengontrolan pemutus hubungan ke beban apabila tegangan akumulator sudah lemah, dan pemutus hubungan dari sumber ke akumulator apabila kondisi akumulator sudah penuh

\section{TINJAUAN PUSTAKA}

Terdapat 2 jenis charge controller yang didasarkan pada cara kerjanya dalam melakukan proses pengisian, diantaranya adalah Pulse Width Modulation (PWM) dan Maximum Power Point Tracker (MPPT)[3][4].

\section{Pulse Width Modulation (PWM)}

Pengontrol ini melakukan proses pengisian dengan cara mengatur modulasi lebar pulsa untuk mengendalikan keberlangsungan proses pengisisan. Kontroler akan memeriksa status akumulator untuk menentukan seberapa cepat dan seberapa besar lebar pulsa yang akan disuplai kontroler. Pada kondisi akumulator hampir penuh dan tidak berbeban, pulsa yang akan disuplai ke akumulator akan sangat kecil setiap detiknya, namun apabila kondisi akumulator sedang berbeban, lebar pulsa ini akan panjang, lama dan berkelanjutan. Alat kontroler jenis ini akan menurunkan jumlah daya yang masuk ke akumulator untuk mengurangi stress pada akumulator apabila kondisi akumulator mendekati penuh. Namun alat ini memiliki keterbatasan yaitu, tegangan alat ini harus sesuai dengan tegangan akumulator yang akan digunakan, kemudian kapasitas maksimum alat ini biasanya sebesar $60 \mathrm{~A}$.

Untuk membangkitkan gelombang PWM menggunakan rangkaian Analog maka dibutuhkan dua buah gelombang, yaitu gelombang Reference dan gelombang Carrier. Pada proses PWM kedua gelombang ini dibandingan untuk mendapatkan kondisi ON dan kondisi OF pada sebuah gelombang PWM[6].

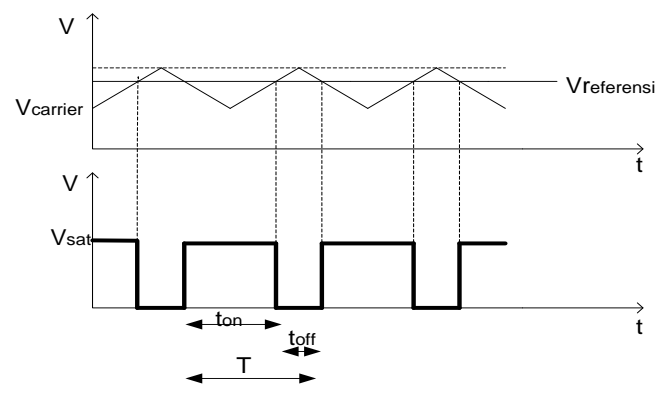

Gambar 1. Proses PWM [9]

$D=\frac{t_{\text {on }}}{\left(t_{\text {on }}+t_{\text {off }}\right)}$

\section{Proses Charging}

Proses charging pada charge controller dalam laporan ini bekerja berdasarkan pengaturan modulasi lebar pulsa (pulse width modulation). Pulse width modulation(PWM) merupakan suatu teknik untuk memperoleh sinyal analog yang diperoleh dari sebuah piranti digital. Hasil keluaran sinyal analog dapat berubah besarnya dengan memberikan inputan berupa sinyal digital dengan bentuk gelombang kotak yang diatur lebar pulsanya (pulse width) pada saat On dan Off atau durasi frekuensi pada saat high $(5 \mathrm{~V})$ dan low (0V)dalam satu periode gelombang. Persentase lamanya periode sinyal pada saat high atau On dengan periode sinyal disebut duty cycle (D) [5][7]. Persentase duty cycle berbanding lurus dengan tegangan keluaran rata-rata yang dihasilkan.

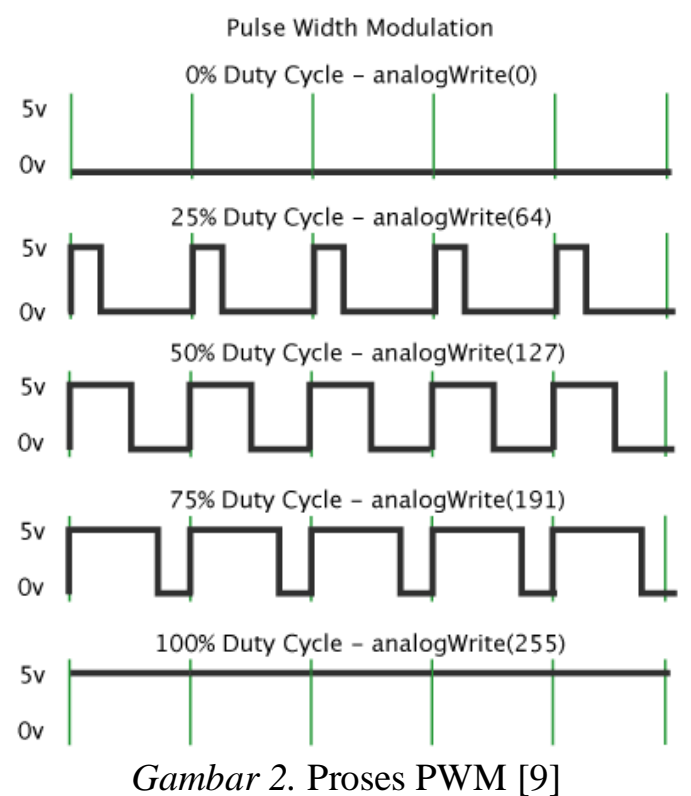

\section{METODOLOGI}

Pada perencanaan dan pembuatan charge controller meliputi rangkaian komponen elektronika charge controller itu sendiri dengan arduino uno R3 sebagai kontrolernya, sumber tegangan DC (energi terbarukan), akumulator dan beberapa komponen pendukung seperti sensor tegangan, power supply dan output berupa LCD sebagai parameternya, mengacu pada gambar blok diagram dibawah.

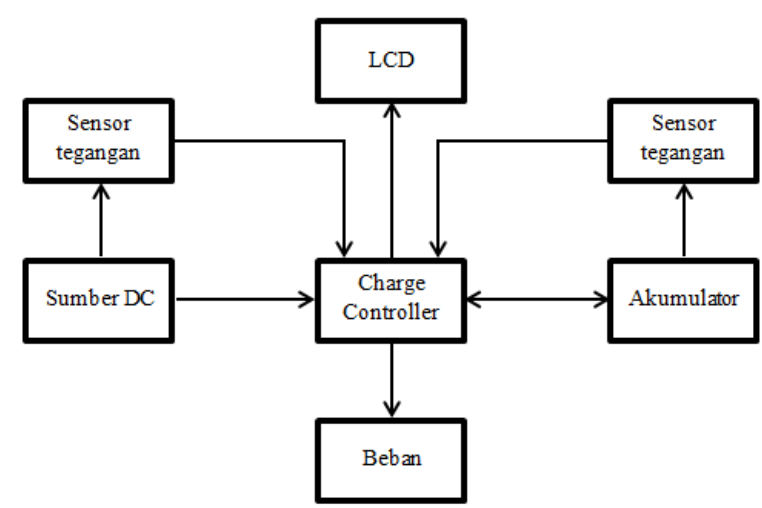

Gambar 3. Blok Diagram Gate Driver[8]

Pada paper ini dirancang sebuah charge controller yang didalamnya terdiri dari beberapa rangkaian, diantaranya adalah rangkaian power supply yang berfungsi untuk menghasilkan supply tenaga untuk 
kontroler, yang mana supply ini diperoleh dari akumulator $12 \mathrm{~V}$, yang juga merupakan akumulator yang sama untuk proses charging, dengan kapasitas 7Ah yang kemudian diregulasi tegangannya menggunakan regulator tegangan berupa IC regulator tegangan seri 7809 untuk menghasilkan tegangan keluaran 9 Volt yang tetap dan stabil. Hasil keluaran dari rangkaian power supply 9 Volt ini akan menjadi inputpower untuk kontroler arduino uno R3. Sumber listrik hybrid charge kontroler merupakan input sumber DC dengan tegangan maksimum 24 Volt yang kemudian akan digunakan untuk men-charge akumulator 12 Volt dengan kapasitas 7Ah sebanyak tiga buah.Charge controller dibuat dengan arus maksimum 5A, agar mampu menyuplai arus yang mengalir dari sumber ke akumulator.

\section{HASIL DAN PEMBAHASAN}
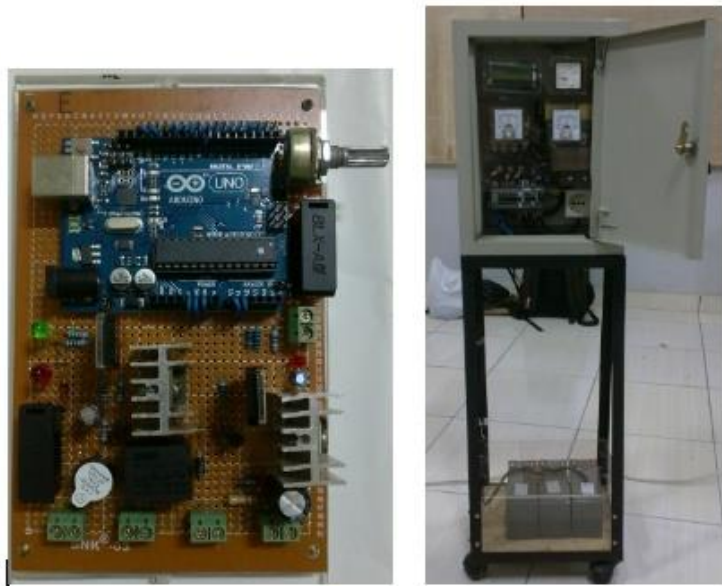

Gambar 4. Rangkaian Realisasi Gate Driver

\section{A. Pengujian Gelombang PWM}

Pada pengujian ini, proses dimulai dari sumber DC yang masuk melalui input charge controller, kemudian akan dilihat gelombang PWM yang dihasilkan untuk men-charge akumulator pada duty cycle 95\%, $10 \%$ dan $0 \%$ dengan ketentuan yang telah dibuat sesuai dengan programnya, termasuk pemutus-sambungan dari akumulator ke beban.

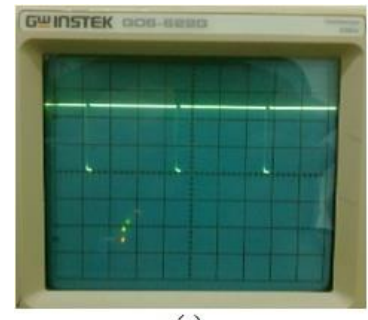

(a)

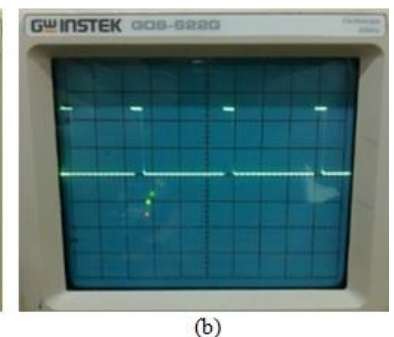

(b)
Gambar 5. duty cycle (a) PWM $95 \%$ (b). PWM $10 \%$

Pada saat pengujian dengan memberikan sumber tegangan DC sebesar 14,12 Volt pada terminal inputan sumber DC dan tanpa ada pengaturan switching (duty cycle 100\%) pada MOSFET, maka pada terminal output yang akan terhubung ke akumulator diperoleh tegangan sebesar 13,24 Volt, sehingga dapat disimpulkan bahwa untuk men-charge akumulator hingga tercapai pada kondisi penuh atau full (tegangan akumulator 14,4 Volt), setidaknya dibutuhkan input sumber tegangan DC di atas $\pm 15,28$ Volt.

Pengujian juga dilakukan dengan men-charge akumulator selama 6 jam, dan dilakukan pengukuran tegangan sumber dan tegangan akumulator setiap jamnya dan pengukuran arus yang mengalir antara power supply ke input charge controller.

\section{B. Pengujian Charger Control}

Pada pengujian, sumber yang menjadi inputan yang akan masuk ke terminal charge controller menggunakan power supply merk Omron tipe S82K0502424 VDC 2,1 A yang kemudian dirangkai paralel dengan regulator tegangan LM7818, sehingga diperoleh keluaran tegangan hybrid (VHY) sebesar 18,28 Volt dan tegangan akumulator (VBT) awal sebesar 12, 55 Volt yang terdiri dari 3 buah akumulator 7Ah.

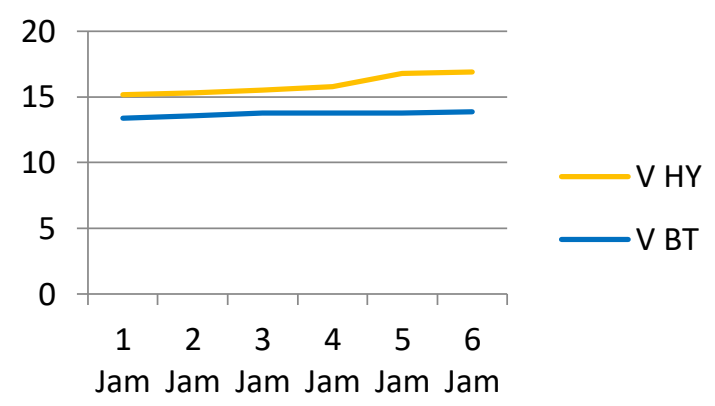

Gambar 6. Grafik Hasil Pengujian

Pada grafik di atas pengukuran tegangan dilakukan saat kondisi terhubung, dan arus yang dialirkan dari sumber yang masuk ke charge controller pada mulanya mencapai 1,5 A yang kemudian turun hingga stabil pada 0,166 A. Arus yang kecil ini dapat disebabkan oleh karena power supply yang digunakan kurang mampu menyuplai dengan maksimal.

Sebelum di-charge:

$\mathrm{V}_{\mathrm{HY}}=18,28$ Volt

$\mathrm{V}_{\mathrm{BT}}=12,55$ Volt

Setelah di-charge :

$\mathrm{V}_{\mathrm{HY}}=18,28$ Volt

$\mathrm{V}_{\mathrm{BT}}=13,14$ Volt

Sehingga berdasarkan pengujian di atas, proses charging dapat berjalan dengan baik.

\section{KESIMPULAN}

Dalam Paper ini telah dilakukan penelitian Proses charging didasarkan pada pengaturan PWM, dan terdiri dari 2 jenis, yaitu boost mode dan float mode yang dibedakan dari pengaturan duty cyclenya. Pembacaan tegangan pada sensor pembagi tegangan memiliki error kurang dari $6,22 \%$ pada terminal sumber, dan $6,89 \%$ pada terminal akumulator. Besarnya persentas duty cycle 
sama dengan perbandingan periode saat On dengan periode 1 gelombang penuh itu sendiri. Tegangan sumber dan akumulator pada saat proses charging mengalami kenaikan seiring waktu berjalan dimana Tegangan akumulator sebelum di-charge sebesar 12,55 Volt, setelah 6 jam Proses charging menjadi 13,14 Volt.

\section{DAFTAR PUSTAKA}

[1] Kurnifan.A. P, dkk, "PENGEMBANGAN ALAT CONTROL CHARGING PANEL SURYA MENGGUNAKAN ARDUINO NANO UNTUK SEPEDA LISTRIK," Jurnal Edukasi Elektro, Vol.2, No.1, Mei 2018.

[2] I Gusti.N.A.M, dkk,"RANCANG BANGUN BATERAI CHARGE CONTROL UNTUK SISTEM PENGANGKAT AIR BERBASIS ARDUINO UNO MEMANFAATKAN SUMBER PLTS," E-Journal SPEKTRUM, Vol.3, No.1, Juni 2016.

[3] C.Y.Sirait dan Hendi Matalata,"PERANCANGAN BOOST CONVERTER DENGAN LDR SEBAGAI PENGENDALI SINYAL PWM," JEPCA, Vol.1, No.2, 2018.

[4] Irfan. M. dkk.,"RANCANG BANGUN SOLAR CHARGER CONTROLLER MENGGUNAKAN SYNCRONOUS NON-INVERTING BUCKBOOST CONVERTER PADA PANEL SURYA 50 WATT PEAK(WP) BERBASIS ARDUINO NANO V3.0," Jurnal pendidikan Vokasi Teknik Elektronika. Vol.1, No.1, April 2018.

[5] Hendi Matalata,"Analisa Buck Converter dan Boost Converter Pada Perubahan Duty Cycle PWM Dengan Membandingkan Frekuensi PWM 1,7 KHz dan 3,3 KHz," Jurnal Ilmiah Universitas Batanghari Jambi, Vol.18, No.1, Februari 2018.

[6] N.MOHAN, book, 1st ed., vol.1. USA:Don Fowley, 2012.

[7] A. Datta, D. Mukherje, and H. Saha." A dsPIC based novel digital sinusoidal pulse-width modulation technique for voltage source inverter applications," microprocess. Microsyst., vol.38, no.7, pp.649-658, 2014.

\section{Biodata Penulis}

Leily.W.Johar, Menyelesaikan pendidikan sarjana di Universitas Bung Hatta jurusan teknik elektro pada tahun 1996. Pada tahun 2017 menyelesaikan pendidikan magister di Universitas Andalas jurusan teknik elektro. Saat ini mengajar di Universitas Batanghari pada jurusan teknik listrik dengan bidang riset teknik tenaga listrik dan proteksi daya listrik. 